BRAVZULIAN JOURNAL

OF MEDICAL AND BIOLOGICAL RESFARCH

www.bjournal.com.br
ISSN 0100-879X

Volume 44 (7) 606-728 July 2011

BIOMEDICAL SCIENCES

AND

CLINICAL INVESTIGATION

Braz J Med Biol Res, July 2011, Volume 44(7) 618-623

doi: 10.1590/S0100-879X2011007500078

Taurine inhibits serum deprivation-induced osteoblast apoptosis via the taurine transporter/ERK signaling pathway

Lei-Yi Zhang, Yue-Ying Zhou, Fei Chen, Bing Wang, Jing Li, You-Wen Deng, Wei-Dong Liu, Zheng-Guang Wang, Ya-Wei Li, Dong-Zhe Li, Guo-Hua Lv and Bang-Liang Yin

The Brazilian Journal of Medical and Biological Research is partially financed by

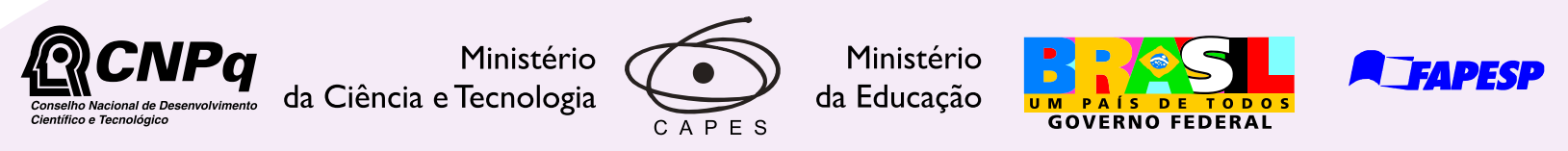

Institutional S ponsors
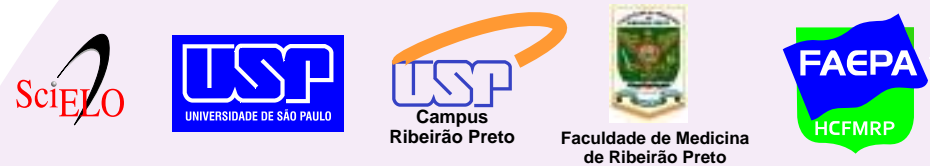


\title{
Taurine inhibits serum deprivation-induced osteoblast apoptosis via the taurine transporter/ERK signaling pathway
}

\author{
Lei-Yi Zhang ${ }^{1}$, Yue-Ying Zhou ${ }^{2}$, Fei Chen ${ }^{1}$, Bing Wang ${ }^{1}$, Jing Li ${ }^{1}$, You-Wen Deng ${ }^{1}$, \\ Wei-Dong Liu' ${ }^{1}$, Zheng-Guang Wang ${ }^{1}$, Ya-Wei Li ${ }^{1}$, Dong-Zhe Li ${ }^{1}$, \\ Guo-Hua Lv ${ }^{1}$ and Bang-Liang Yin ${ }^{3}$ \\ ${ }^{1}$ Department of Spine Surgery, ${ }^{2}$ Department of Stomatology, \\ ${ }^{3}$ Department of Cardiothoracic Surgery, Second Xiangya Hospital, \\ Central South University, Changsha, Hunan, China
}

\begin{abstract}
Taurine has positive effects on bone metabolism. However, the effects of taurine on osteoblast apoptosis in vitro have not been reported. The aim of this study was to investigate the activity of taurine on apoptosis of mouse osteoblastic MC3T3-E1 cells. The data showed that 1, 5, 10, or $20 \mathrm{mM}$ taurine resulted in 16.7, 34.2, 66.9, or 63.7\% reduction of MC3T3-E1 cell apoptosis induced by the serum deprivation (serum-free $\alpha-M E M)$, respectively. Taurine $(1,5$, or $10 \mathrm{mM})$ also reduced cytochrome c release and inhibited activation of caspase- 3 and -9 , which were measured using fluorogenic substrates for caspase-3/caspase- 9 , in serum-deprived MC3T3-E1 cells. Furthermore, taurine $(10 \mathrm{mM})$ induced extracellular signal-regulated kinase (ERK) phosphorylation in MC3T3-E1 cells. Knockdown of the taurine transporter (TAUT) or treatment with the ERK-specific inhibitor PD98059 $(10 \mu \mathrm{M})$ blocked the activation of ERK induced by taurine $(10 \mathrm{mM})$ and abolished the anti-apoptotic effect of taurine (10 mM) in MC3T3-E1 cells. The present results demonstrate for the first time that taurine inhibits serum deprivation-induced osteoblast apoptosis via the TAUT/ERK signaling pathway.
\end{abstract}

Key words: Taurine; Osteoblasts; Apoptosis; Taurine transporter; ERK

\section{Introduction}

Taurine is a sulfur-containing $\beta$-amino acid that exists in free form in mammals. Various physiological roles have been reported for taurine, including calcium modulation, membrane stabilization, osmoregulation, neuromodulation, antioxidation, and regulation of protein phosphorylation $(1,2)$. Taurine is necessary for certain aspects of mammalian development, and its deficiency leads to defects in growth, tissue differentiation, and immune development $(1,2)$.

Studies have indicated that bone tissue contains high concentrations of taurine $(3,4)$, which emerges as an element in the regulation of bone metabolism (5-9). Taurine supplementation prevented bone loss in ovariectomized rats $(8,9)$. Koide et al. (10) reported that taurine reduced alveolar bone resorption in experimental animals. In vitro studies demonstrated that the taurine transporter (TAUT), a specific taurine transport system, was expressed in osteoblasts and osteoclast precursors $(11,12)$. Taurine promoted osteoblast proliferation and differentiation $(4,11)$ and stimulated connective tissue growth factor expression in osteoblasts through the extracellular signal-regulated kinase (ERK) pathway (13), while it inhibited osteoclastogenesis via the TAUT $(12,14)$. These findings indicate that taurine is beneficial for bone metabolism. However, no data have been published about the effect of taurine on osteoblast apoptosis.

The rate of bone formation and resorption is largely determined by the numbers of bone-forming (osteoblast) and bone-resorbing (osteoclast) cells present in the basic multicellular units responsible for the regeneration of the adult skeleton $(15,16)$. As is the case for other regenerating tissues, the number of bone cells is controlled by changes not only in the production of mature cells, but also in their survival. The majority of osteoblasts die by apoptosis. The

Correspondence: Guo-Hua Lv and Bang-Liang Yin, Department of Spine Surgery, Second Xiangya Hospital, Central South University, 139\# Middle Renmin Road, Changsha, Hunan 410011, China. Fax: +86-731-8265-0262.

E-mail: guohualv@yahoo.com.cn or bly_csu@yahoo.cn

Received December 11, 2010. Accepted June 1, 2011. Available online June 24, 2011. Published July 25, 2011. 
frequency of osteoblast apoptosis could have a significant impact on the number of osteoblasts present at the site of bone formation (17-19).

The present study was undertaken to determine whether taurine regulates serum deprivation-induced apoptosis of osteoblastic MC3T3-E1 cells and to examine the mechanisms by which taurine acts on cell apoptosis.

\section{Material and Methods}

\begin{abstract}
Material
Bovine serum albumin (BSA), anti- $\beta$-actin antibody and $\alpha$-minimum essential medium ( $\alpha$-MEM) were purchased from Sigma (USA). Fetal bovine serum (FBS) was purchased from Gibco-BRL Corp. (USA). Polyvinylidene difluoride (PVDF) membrane was purchased from Amersham Pharmacia Biotech (USA). Anti-TAUT antibody was purchased from Alpha Diagnostic Inc. (USA). Anti-cytochrome c, anti-ERK1/2 and anti-p-ERK1/2 antibodies and horseradish peroxidase (HRP)conjugated secondary antibodies were purchased from Santa Cruz Biotechnology (USA).
\end{abstract}

\section{Cell apoptosis measurement}

Apoptosis was assessed directly by measurement of cytoplasmic nucleosomes (i.e., DNA complexed with histone in the cytoplasm) using a Cell Death Detection ELISA kit (Roche Diagnostics $\mathrm{GmbH}$, Roche Molecular Biochemicals, Germany) according to the protocol provided by the manufacturer. This kit allows a specific determination of mono- and oligo-nucleosomes in the cytoplasmic fraction of cell lysates $(20,21)$.

\section{Western blot analysis}

Western blot analysis was performed as previously described (22-26). Cells were lysed and protein concentrations were determined by the Bradford assay with BSA used as standard. Equal amounts of protein ( $40 \mu \mathrm{g} / \mathrm{lane})$ were separated by SDS gel electrophoresis and transferred to a PVDF membrane. To detect TAUT expression and ERK1/2 phosphorylation, the membranes were probed with primary antibodies overnight at $4^{\circ} \mathrm{C}$, followed by the appropriate HRP-conjugated secondary antibodies for $1 \mathrm{~h}$ at room temperature.

To analyze the release of cytochrome $c$ from the mitochondria into the cytosol, the cell lysates were centrifuged at $100,000 \mathrm{~g}$ for $30 \mathrm{~min}$ to yield the soluble cytosolic fraction (supernatant). Supernatants were then subjected to Western blot analysis as described above with anti-cytochrome c antibody.

The blots were visualized by the chemiluminescent detection method using the SuperSignal West Pico Substrate (Pierce, USA).

\section{Assays for caspase- 3 and caspase-9 \\ Cells were lysed with lysis buffer containing $10 \mathrm{mM}$ HEPES, pH 7.5, 0.5\% Nonidet P-40, 0.5 mM EDTA, 150}

$\mathrm{mM} \mathrm{NaCl}$, and $2 \mathrm{mM}$ phenylmethylsulfonyl fluoride. Aliquots of the extracts were incubated for $1 \mathrm{~h}$ at $37^{\circ} \mathrm{C}$ with $50 \mathrm{mM}$ enzyme substrate [acetyl-DEVD-4-methyl-coumaryl-7-amide (Ac-DEVD-MCA) for caspase-3-like proteinase and $\mathrm{N}$ acetyl-Leu-Glu-His-Asp-(7-amino-4-trifluoromethylcoumarin) (Ac-LEHD-AFC) for caspase-9-like proteinase] in a reaction mixture containing $10 \mathrm{mM}$ HEPES, pH 7.5, $50 \mathrm{mM} \mathrm{NaCl}$, and $2.5 \mathrm{mM}$ dithiothreitol. The fluorescence of the released 7-amino-4-methylcoumarin (AMC) was measured with a spectrofluorometer at an excitation wavelength of $380 \mathrm{~nm}$ and an emission wavelength of $460 \mathrm{~nm}$. AFC release was monitored at an excitation wavelength of $400 \mathrm{~nm}$ and an emission wavelength of $505 \mathrm{~nm}$.

\section{RNA interference for TAUT}

RNA interference was used to down-regulate the expression of TAUT in MC3T3-E1 cells as previously described (12). TAUT-small interfering RNA (siRNA) and control-siRNA were synthesized by Genesil Biotechnology Co. (China). The target sense sequence of mouse TAUT is: GATCTGT CCTTTGTTCTCTTT. For gene knockdown experiments, MC3T3-E1 cells were cultured for $24 \mathrm{~h}$ in a-MEM without antibiotics, then transfected with siRNAs $(0.4 \mathrm{nmol} /$ well) using lipofectamine 2000 (Invitrogen Inc., USA) according to the protocol provided by the manufacturer. Cells were retransfected with siRNAs $24 \mathrm{~h}$ after the initial transfection and the siRNA effect was analyzed $48 \mathrm{~h}$ later.

\section{Taurine uptake measurement}

Taurine uptake by MC3T3-E1 cells was assayed as previously described $(12,27)$. Cells were washed twice at $37^{\circ} \mathrm{C}$ with the uptake medium (containing $20 \mathrm{mM}$ HEPES, $140 \mathrm{mM} \mathrm{NaCl}, 5.4 \mathrm{mM} \mathrm{KCl}, 1.8 \mathrm{mM} \mathrm{CaCl}_{2}, 0.8 \mathrm{mM} \mathrm{MgSO}_{4}$, and $5 \mathrm{mM}$ glucose) and equilibrated in $2 \mathrm{~mL}$ taurine uptake buffer at $37^{\circ} \mathrm{C}$. Taurine uptake was initiated by adding an uptake buffer containing $1 \mu \mathrm{Ci}\left[{ }^{3} \mathrm{H}\right]$-taurine and increasing the concentrations of the unlabeled substances. After incubation for $20 \mathrm{~min}$, the cells were rapidly washed with cold PBS containing $0.05 \%$ sodium azide and lysed with $0.1 \mathrm{M} \mathrm{NaOH}$. The radioactivity of the lysates was measured by liquid scintillation spectrometry. The sixth well was used to measure the average protein content by the Bradford assay.

\section{Statistical analyses}

SPSS 13.0 was used for the statistical analyses. Data are reported as means $\pm S D$ of quintuplicate assays. Comparisons were made using one-way ANOVA. All experiments were repeated at least three times and representative results are shown.

\section{Results}

Taurine protected MC3T3-E1 cells against serum deprivation-induced apoptosis

MC3T3-E1 cells in 1\% FBS medium showed basal 


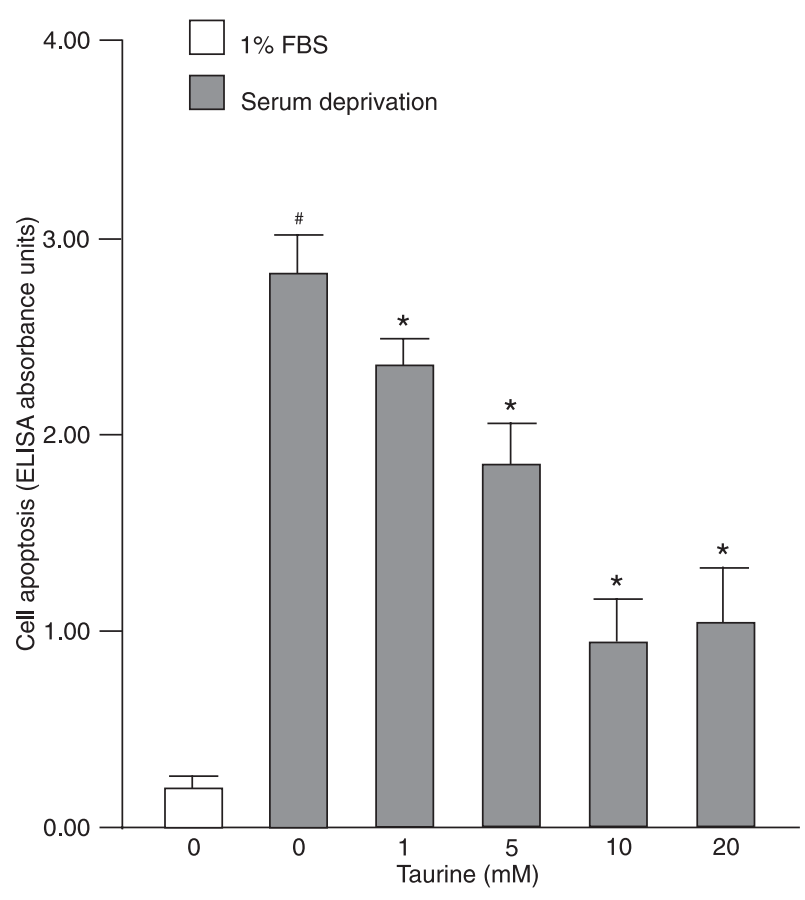

Figure 1. Effect of taurine on serum deprivation-induced apoptosis of MC3T3-E1 cells. Cells were treated with 1 to $20 \mathrm{mM}$ taurine in serum-free a-MEM for $48 \mathrm{~h}$. Apoptosis was assessed using a Cell Death Detection kit, and reported as ELISA absorbance units. The bars indicate the mean $\pm S D(N=5)$. $\# P<0.05$ vs $1 \%$ FBS-treated control; ${ }^{*} \mathrm{P}<0.05$ vs vehicle-treated serum-deprived group (one-way ANOVA).

levels of apoptosis; 1 to $10 \mathrm{mM}$ taurine dose-dependently protected MC3T3-E1 cells against serum deprivationinduced apoptosis (Figure 1).

\section{Taurine reduced cytochrome c release and inhibited activation of caspase- 3 and -9 in serum-deprived MC3T3-E1 cells}

Cytochrome $c$ was released into the cytoplasm in the serum-free culture; however, the release was reduced in the presence of 1 to $10 \mathrm{mM}$ taurine (Figure 2A). Serum deprivation-induced activation of caspase- 3 and -9 was also markedly decreased in 1 to $10 \mathrm{mM}$ taurine-treated cells (Figure 2B).

\section{TAUT knockdown with siRNA inhibited $\left[{ }^{3} \mathrm{H}\right]$-taurine uptake in MC3T3-E1 cells}

Western blot analysis revealed that TAUT protein expression $(70 \mathrm{kDa})$ was demonstrable in MC3T3-E1 cells (Figure $3 \mathrm{~A}$ ). This confirms a previous study showing that TAUT is expressed in MC3T3-E1 cells (11). Treatment with siRNA-TAUT but not siRNA-control suppressed the expression of TAUT protein in MC3T3-E1 cells (Figure $3 \mathrm{~A})$, and inhibited $\left[{ }^{3} \mathrm{H}\right]$-taurine uptake in these cells (Figure 3B).

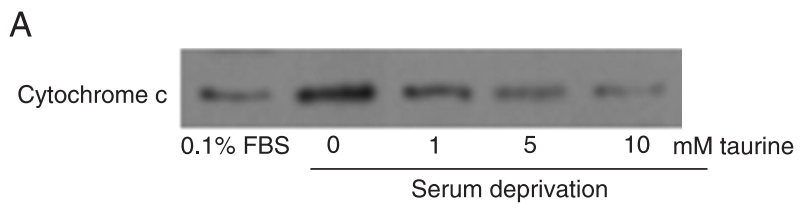

B
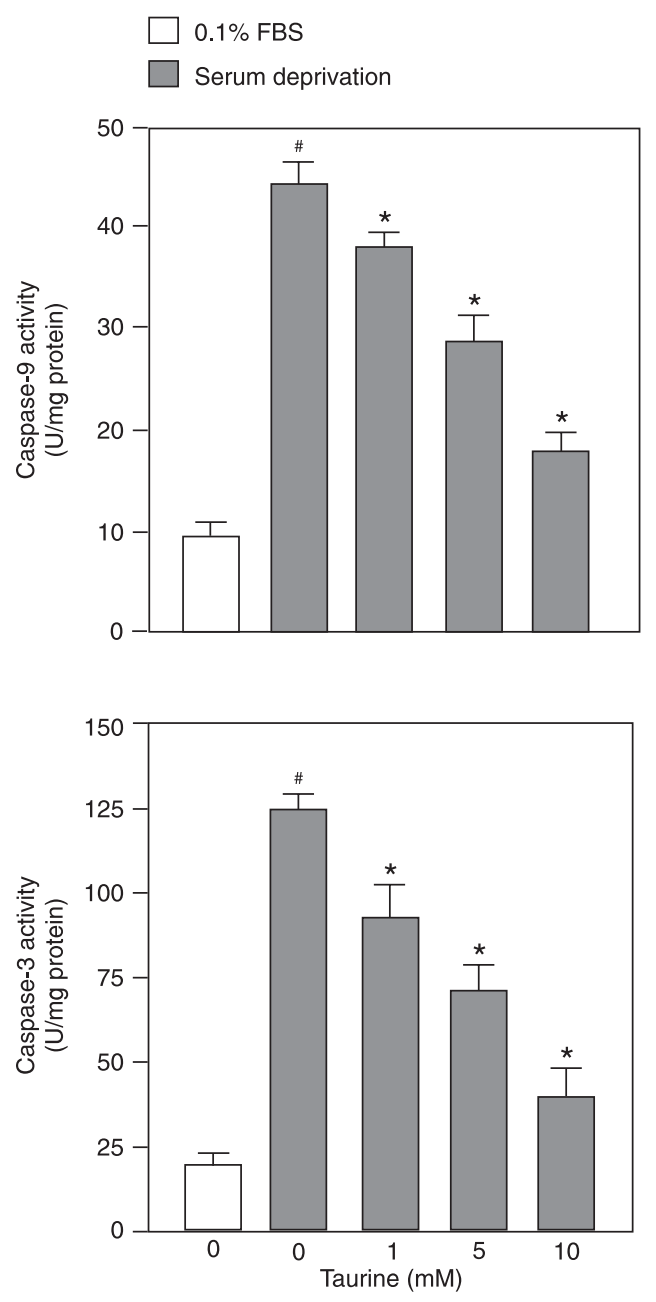

Figure 2. Effects of taurine on cytochrome $c$ release and caspase-3 and -9 activation in serum-deprived MC3T3-E1 cells. A, Western blot analysis of the effect of taurine on cytochrome $c$ release. Cells were grown in the absence or presence of $0.1 \%$ FBS in a-MEM for $24 \mathrm{~h}$ and serum-deprived cells were treated with vehicle or 1 to $10 \mathrm{mM}$ taurine for $24 \mathrm{~h}$. Representative results are shown. $B$, Fluoro-substrate assays of the effects of taurine on serum deprivation-induced activation of caspase-3 and -9. Cells were grown in the absence or presence of $0.1 \%$ FBS in a-MEM for $1.5 \mathrm{~h}$ and serum-deprived cells were treated with vehicle or 1 to $10 \mathrm{mM}$ taurine for $1.5 \mathrm{~h}$. One unit $(\mathrm{U})$ was defined as the amount of enzyme required to release $1 \mu \mathrm{M}$ 7-amino-4-methylcoumarin (AMC) per hour at $37^{\circ} \mathrm{C}$. The bars indicate the mean \pm $\mathrm{SD}(\mathrm{N}=5)$. ${ }^{\#} \mathrm{P}<0.05$ vs $0.1 \%$ FBS-treated control; ${ }^{*} \mathrm{P}<0.05$ vs vehicle-treated serum-deprived group (one-way ANOVA). 

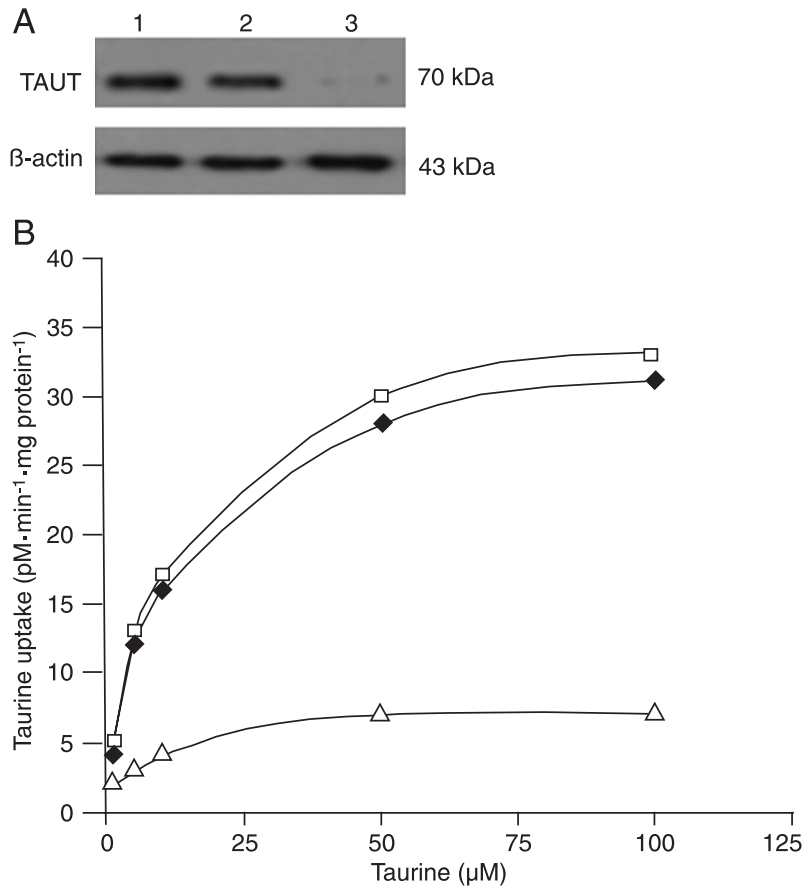

Figure 3. Effects of siRNA-TAUT on TAUT protein expression and taurine uptake in MC3T3-E1 cells. A, Total cell lysates were subjected to Western blot analysis and representative results are shown. Lane 1: MC3T3-E1 cells; lane 2: siRNA-control-transfected MC3T3-E1 cells; lane 3: siRNA-TAUT-transfected MC3T3-E1 cells. $B$, Uptake of $\left[{ }^{3} \mathrm{H}\right]$-taurine by MC3T3-E1 cells (open squares), siRNA-control-transfected MC3T3-E1 cells (filled diamonds), and siRNA-TAUT-transfected MC3T3-E1 cells (open triangles). TAUT $=$ taurine transporter

\section{Taurine activated ERK1/2 signaling pathway via TAUT in MC3T3-E1 cells}

Taurine enhanced the levels of phosphorylated ERK1/2 within 5 min of incubation and the peak activation of ERK1/2 occurred at 15 min (Figure 4A). The activation of ERK1/2 by taurine was abolished by PD98059 (an inhibitor of ERK) (Figure 4B). Moreover, knockdown of TAUT with siRNA blocked the activation of ERK1/2 induced by taurine (Figure 4B). These data indicate that taurine stimulates ERK1/2 activation via TAUT in MC3T3-E1 cells.

\section{The TAUT/ERK signaling pathway mediates the anti-apoptotic effect of taurine in MC3T3-E1 cells}

The anti-apoptotic effect of taurine in MC3T3-E1 cells was abolished by pretreatment with the ERK inhibitor PD98059, and was also blocked by knockdown of TAUT with siRNA (Figure 5). These data indicate that the anti-apoptotic activity of taurine is mediated by the TAUT/ERK signaling pathway.

\section{Discussion}

We demonstrated here that taurine protected MC3T3-E1
A
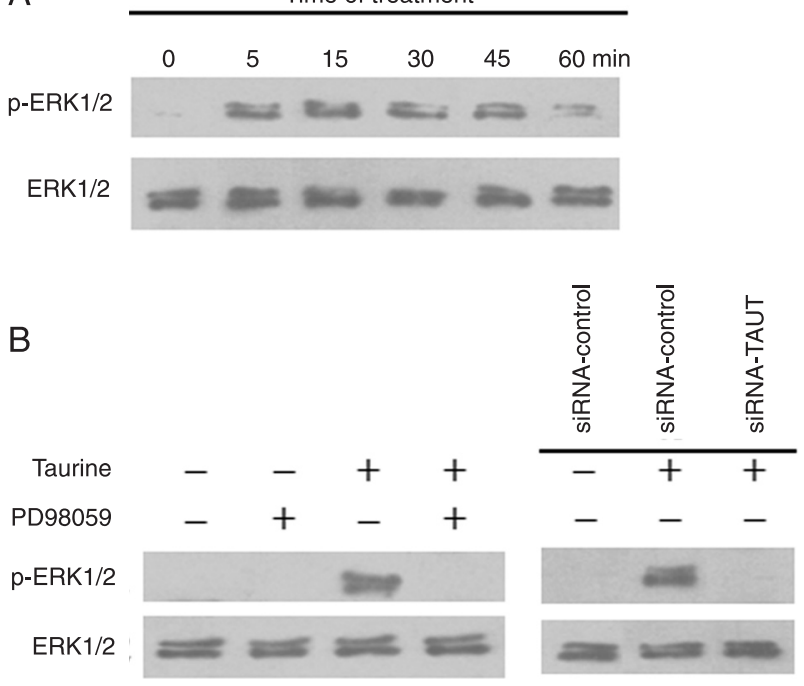

Figure 4. Effect of taurine on ERK1/2 activation in MC3T3-E1 cells. Cell lysates were subjected to Western blot using antibodies against $p$-ERK1/2 and ERK1/2. Representative results are shown. $A$, Cells exposed to $10 \mathrm{mM}$ taurine for 5 to $60 \mathrm{~min}$. $B$, Cells incubated with $10 \mu \mathrm{M}$ PD98059 for $3 \mathrm{~h}$ prior to treatment with $10 \mathrm{mM}$ taurine for $15 \mathrm{~min}$. Both siRNA-control- and siRNATAUT-transfected cells were treated with $10 \mathrm{mM}$ taurine for 15 min. ERK = extracellular signal-regulated kinase; TAUT = taurine transporter; siRNA = small interfering RNA.

cells against apoptosis induced by serum deprivation via the TAUT/ERK signaling pathway.

On the basis of its multiple functions, taurine may protect cells against various types of injury (28). In the present study, taurine suppressed serum deprivation-induced apoptosis of MC3T3-E1 cells, indicating an anti-apoptotic role of taurine in addition to its mitogenic and osteogenic effects on osteoblasts. Taurine content in bone is similar to that in liver or kidney ( 2 to $11 \mathrm{mM} / \mathrm{kg}$ tissue) $(3,4,29)$. Thus, the effects of taurine on the suppression of osteoblast apoptosis were physiologically relevant in the present experiments.

Although the exact mechanisms of serum deprivationinduced apoptosis have not been completely elucidated, mitochondria have been shown to play an important role $(30,31)$. Translocation of cytochrome c into the cytosol is the primary event in the mitochondrial pathway that leads to the formation of apoptosomes and activation of the caspase cascade. Once cytochrome c enters the cytosol, it associates with apoptotic peptidase activating factor 1 and dATP to form an apoptosome. Apoptosomes recruit and activate caspase-9, an initiator caspase, which in turn activates other downstream executioner caspases, such as caspase-3. The active executioner caspases are responsible for cleaving their target substrates to induce apoptosis $(30,31)$. In this study, the induction of cytochrome c release and caspase- 9 and -3 activation by serum deprivation in MC3T3-E1 cells agrees with previous reports 


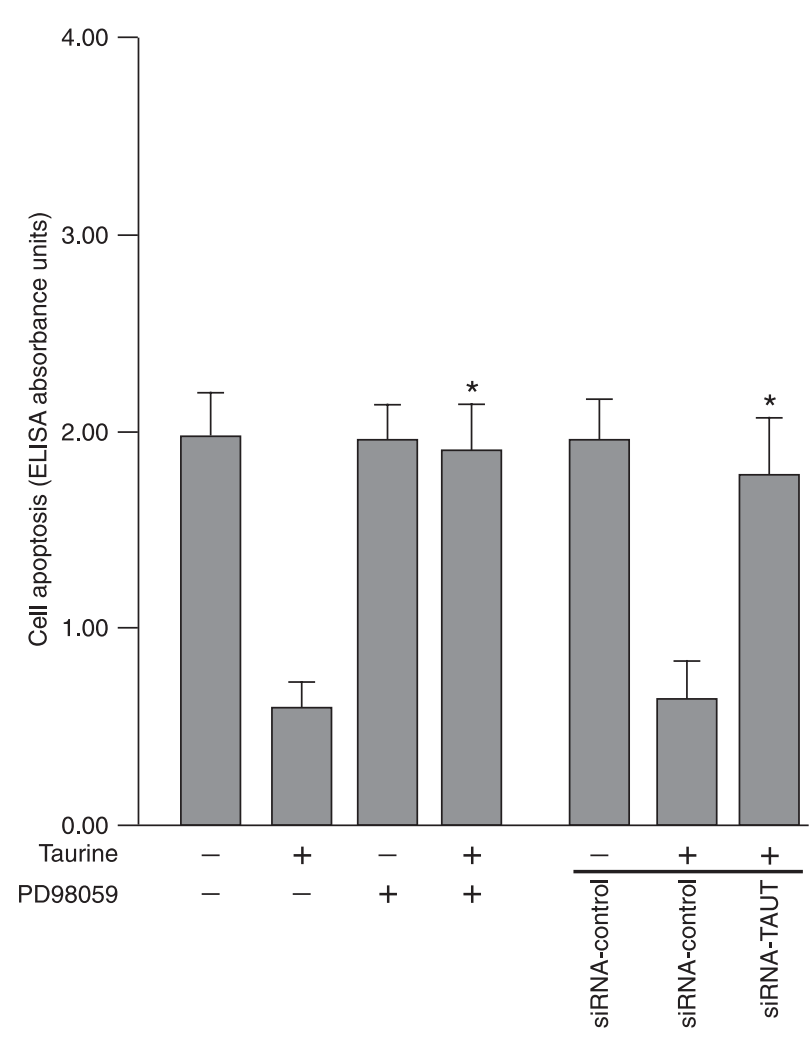

Figure 5. TAUT and ERK signaling pathways mediate the antiapoptotic effect of taurine on MC3T3-E1 cells. Serum-deprived cells were incubated with $10 \mu \mathrm{M}$ PD98059 for $3 \mathrm{~h}$ prior to treatment with $10 \mathrm{mM}$ taurine for $48 \mathrm{~h}$. Both siRNA-control- and siRNA-TAUT-transfected cells were cultured in serum-deprived media and treated with $10 \mathrm{mM}$ taurine for $48 \mathrm{~h}$. Cell apoptosis was determined with a Cell Death Detection kit, and reported as ELISA absorbance units. The bars indicate the mean \pm SD $(\mathrm{N}=5)$. TAUT = taurine transporter; ERK = extracellular signalregulated kinase; siRNA $=$ small interfering $\mathrm{RNA}$. ${ }^{*} \mathrm{P}<0.05$ vs taurine-treated control (one-way ANOVA).

(32-34). Moreover, there have been reports showing that taurine was capable of suppressing apoptosis through the mitochondrial pathway in retinal ganglion cells (35), hepatocytes (36), and testicular tissue (37). In the present study, with taurine treatment, the serum deprivation-induced release of cytochrome $\mathrm{c}$ from the mitochondria was reduced

\section{References}

1. Bouckenooghe $T$, Remacle C, Reusens B. Is taurine a functional nutrient? Curr Opin Clin Nutr Metab Care 2006; 9: 728-733.

2. Oja SS, Saransaari P. Pharmacology of taurine. Proc West Pharmacol Soc 2007; 50: 8-15.

3. Terauchi A, Nakazaw A, Johkura K, Yan L, Usuda N. Immu- and the activation of caspase- 9 and -3 was suppressed. Therefore, taurine suppresses the apoptosis of MC3T3-E1 cells via a mitochondria-dependent pathway.

Taurine is known to be transported by a specific transporter, the TAUT. In the intracellular space, taurine is present in millimolar concentrations, whereas it is found at the concentration of 20 to $100 \mu \mathrm{M}$ in plasma (38), suggesting that TAUT plays an important role in maintaining a high concentration of taurine in cells. The TAUT knockout mouse exhibited retinal degeneration and a marked impairment of reproduction (39), indicating that TAUT is a functional protein. A previous study showed that TAUT was expressed in osteoblasts (11), and could take up [ $\left.{ }^{3} \mathrm{H}\right]$-taurine in these cells (11). In the present study, we showed that knockdown of the TAUT blocked the taurine uptake function of MC3T3E1 cells, and abolished the anti-apoptotic activity of taurine. These data indicate that TAUT mediates the anti-apoptotic action of taurine in MC3T3-E1 cells.

To gain further insight into the mechanisms by which taurine inhibits osteoblast apoptosis, we examined intracellular signaling pathways. The ERK pathway is a critical regulator of cell apoptosis (40). The activation of ERK1/2 induced by taurine observed here is consistent with a previous report that taurine stimulates phosphorylation of ERK1/2, but not p38 and JNK in MC3T3-E1 cells (13). Either TAUT knockdown or treatment with the ERK-specific inhibitor PD98059 blocked ERK1/2 activation induced by taurine and abolished the anti-apoptotic effect of taurine in MC3T3-E1 cells. The TAUT/ERK-dependent inhibition of MC3T3-E1 cell apoptosis by taurine found here agrees with a previous study showing that taurine restores Gas 6 and AxI expression in a vascular smooth muscle cell calcification model through the TAUT/ERK signaling pathway (23).

In conclusion, the present data demonstrate for the first time that taurine inhibits osteoblast apoptosis through the TAUT/ERK signaling pathway, in association with the down-regulation of mitochondria-dependent signaling molecules. The anti-apoptotic action of taurine in osteoblasts may contribute to its bone-sparing effect.

\section{Acknowledgments}

Research supported by the Science and Technology Project of the Science and Technology Bureau, Hunan Province (\#2010FJ4053). nohistochemical localization of taurine in various tissues of the mouse. Amino Acids 1998; 15: 151-160.

4. Park S, Kim H, Kim SJ. Stimulation of ERK2 by taurine with enhanced alkaline phosphatase activity and collagen synthesis in osteoblast-like UMR-106 cells. Biochem Pharmacol 2001; 62: 1107-1111. 
5. Gupta RC, Kim SJ. Taurine, analogues and bone: a growing relationship. Adv Exp Med Biol 2003; 526: 323-328.

6. Gupta RC. Taurine analogues and taurine transport: therapeutic advantages. Adv Exp Med Biol 2006; 583: 449-467.

7. D'Eufemia P, Finocchiaro R, Zambrano A, Tetti M, Ferrucci $\mathrm{V}$, Celli M. Reduction of plasma taurine level in children affected by osteogenesis imperfecta during bisphosphonate therapy. Biomed Pharmacother 2007; 61: 235-240.

8. Cheong SH, Chang KJ. The preventive effect of fermented milk supplement containing tomato (Lycopersion esculentum) and taurine on bone loss in ovariectomized rats. Adv Exp Med Biol 2009; 643: 333-340.

9. Choi MJ, DiMarco NM. The effects of dietary taurine supplementation on bone mineral density in ovariectomized rats. Adv Exp Med Biol 2009; 643: 341-349.

10. Koide M, Okahashi N, Tanaka R, Kazuno K, Shibasaki K, Yamazaki $Y$, et al. Inhibition of experimental bone resorption and osteoclast formation and survival by 2 -aminoethanesulphonic acid. Arch Oral Biol 1999; 44: 711-719.

11. Yuan LQ, Xie H, Luo XH, Wu XP, Zhou HD, Lu Y, et al. Taurine transporter is expressed in osteoblasts. Amino Acids 2006; 31: 157-163.

12. Yuan LQ, Liu W, Cui RR, Wang D, Meng JC, Xie H, et al. Taurine inhibits osteoclastogenesis through the taurine transporter. Amino Acids 2010; 39: 89-99.

13. Yuan LQ, Lu Y, Luo XH, Xie H, Wu XP, Liao EY. Taurine promotes connective tissue growth factor (CTGF) expression in osteoblasts through the ERK signal pathway. Amino Acids 2007; 32: 425-430.

14. Kum KY, Park JH, Yoo YJ, Choi BK, Lee HJ, Lee SJ. The inhibitory effect of alendronate and taurine on osteoclast differentiation mediated by Porphyromonas gingivalis sonicates in vitro. J Endod 2003; 29: 28-30.

15. Manolagas SC. Birth and death of bone cells: basic regulatory mechanisms and implications for the pathogenesis and treatment of osteoporosis. Endocr Rev 2000; 21: 115-137.

16. Jilka RL. Biology of the basic multicellular unit and the pathophysiology of osteoporosis. Med Pediatr Oncol 2003; 41: $182-185$.

17. Weinstein RS, Manolagas SC. Apoptosis and osteoporosis. Am J Med 2000; 108: 153-164.

18. Hock JM, Krishnan V, Onyia JE, Bidwell JP, Milas J, Stanislaus D. Osteoblast apoptosis and bone turnover. J Bone Miner Res 2001; 16: 975-984.

19. Xing L, Boyce BF. Regulation of apoptosis in osteoclasts and osteoblastic cells. Biochem Biophys Res Commun 2005; 328: 709-720.

20. Xie H, Yuan LQ, Luo XH, Huang J, Cui RR, Guo LJ, et al. Apelin suppresses apoptosis of human osteoblasts. Apoptosis 2007; 12: 247-254.

21. Xie H, Tang LL, Luo XH, Wu XY, Wu XP, Zhou HD, et al. Suppressive effect of dexamethasone on TIMP-1 production involves murine osteoblastic MC3T3-E1 cell apoptosis. Amino Acids 2010; 38: 1145-1153.

22. Xie H, Sun M, Liao XB, Yuan LQ, Sheng ZF, Meng JC, et al. Estrogen receptor alpha36 mediates a bone-sparing effect of 17 beta-estrodiol in postmenopausal women. $J$ Bone Miner Res 2011; 26: 156-168.

23. Liao XB, Peng YQ, Zhou XM, Yang B, Zheng Z, Liu LM, et al. Taurine restores AxI/Gas6 expression in vascular smooth muscle cell calcification model. Amino Acids 2010; 39: 375383.

24. Xie H, Tang SY, Cui RR, Huang J, Ren XH, Yuan LQ, et al. Apelin and its receptor are expressed in human osteoblasts. Regul Pept 2006; 134: 118-125.

25. Li H, Xie H, Liu W, Hu R, Huang B, Tan YF, et al. A novel microRNA targeting HDAC5 regulates osteoblast differentiation in mice and contributes to primary osteoporosis in humans. J Clin Invest 2009; 119: 3666-3677.

26. Xie H, Tang SY, Luo XH, Huang J, Cui RR, Yuan LQ, et al. Insulin-like effects of visfatin on human osteoblasts. Calcif Tissue Int 2007; 80: 201-210.

27. Xie H, Yang B, Zhou XM, Song FL, Li JM, Zhou K, et al. Lcarnitine and taurine synergistically inhibit the proliferation and osteoblastic differentiation of vascular smooth muscle cells. Acta Pharmacol Sin 2010; 31: 289-296.

28. Warskulat U, Borsch E, Reinehr R, Heller-Stilb B, Roth C, Witt $M$, et al. Taurine deficiency and apoptosis: findings from the taurine transporter knockout mouse. Arch Biochem Biophys 2007; 462: 202-209.

29. Lubec B, Ya-hua Z, Pertti S, Pentti T, Kitzmuller E, Lubec G. Distribution and disappearance of the radiolabeled carbon derived from L-arginine and taurine in the mouse. Life Sci 1997; 60: 2373-2381.

30. Jeong SY, Seol DW. The role of mitochondria in apoptosis. BMB Rep 2008; 41: 11-22.

31. Wang C, Youle RJ. The role of mitochondria in apoptosis. Annu Rev Genet 2009; 43: 95-118.

32. Tang SY, Xie H, Yuan LQ, Luo XH, Huang J, Cui RR, et al. Apelin stimulates proliferation and suppresses apoptosis of mouse osteoblastic cell line MC3T3-E1 via JNK and PI3-K/ Akt signaling pathways. Peptides 2007; 28: 708-718.

33. Xie H, Tang SY, Li H, Luo XH, Yuan LQ, Wang D, et al. Lcarnitine protects against apoptosis of murine MC3T3-E1 osteoblastic cells. Amino Acids 2008; 35: 419-423.

34. Wang QP, Xie H, Yuan LQ, Luo XH, Li H, Wang D, et al. Effect of progesterone on apoptosis of murine MC3T3-E1 osteoblastic cells. Amino Acids 2009; 36: 57-63.

35. Chen K, Zhang Q, Wang J, Liu F, Mi M, Xu H, et al. Taurine protects transformed rat retinal ganglion cells from hypoxiainduced apoptosis by preventing mitochondrial dysfunction. Brain Res 2009; 1279: 131-138.

36. Lakshmi DS, Anuradha CV. Mitochondrial damage, cytotoxicity and apoptosis in iron-potentiated alcoholic liver fibrosis: amelioration by taurine. Amino Acids 2010; 38: 869-879.

37. Das J, Ghosh J, Manna P, Sinha M, Sil PC. Taurine protects rat testes against $\mathrm{NaAsO}_{2}$-induced oxidative stress and apoptosis via mitochondrial dependent and independent pathways. Toxicol Lett 2009; 187: 201-210.

38. Huxtable RJ. Physiological actions of taurine. Physiol Rev 1992; 72: 101-163.

39. Heller-Stilb B, van Roeyen C, Rascher K, Hartwig HG, Huth A, Seeliger MW, et al. Disruption of the taurine transporter gene (taut) leads to retinal degeneration in mice. FASEB $J$ 2002; 16: 231-233.

40. Ramos JW. The regulation of extracellular signal-regulated kinase (ERK) in mammalian cells. Int J Biochem Cell Biol 2008; 40: 2707-2719. 